\title{
Preliminary Design on the Development of Wireless Sensor Network for Water Table Monitoring in Paddy Fields
}

\author{
Santhosh Simon and K Poulose Jacob \\ Department of Computer Science, Cochin University of Science and Technology \\ Cochin 682 022,Kerala, India. \\ simon.santhosh@gmail.com
}

\begin{abstract}
In the past few years new trends have emerged in the Indian Agricultural sector due to the development in the field of wireless sensor networks as well as other precision agricultural techniques. Through agriculture it is possible to increase the crop production while reducing the cost for cultivation. The farmers can monitor the soil condition, crop ad climate for making alternate arrangements for achieving high yield. Precision agriculture system will gather information from a distributed system of sensors deployed in the fields about the soil moisture, humidity, crop growth, soil nutrients etc. Also it uses a decision support system to suggest the possible treatment for better crop. Examples of suggestion for treatments or corrective measures can be applying a different fertilizer, lime or pesticides. This paper presents the initial design for a paddy field monitoring system using wireless sensor networks. The proposed system will be a distributed wireless sensor network and will communicate to their superior nodes to deliver the collected information.
\end{abstract}

\section{KEYWORDS}

Wireless sensor networks, Precision agriculture.

\section{INTRODUCTION}

Kerala is a small but beautiful state of India lying between 8018 ' to 12048 ' N latitude of 74025 ' to 77025 ' E latitude. The highly fertile land of Kerala commits of high lands, mid lands and low lands. The main crops in the high land are tea, coffee, rubber and spices. The mid lands counting of hills and valleys produces crops like Cashew, Coconut, Tapioca, Banana, Rice etc. The low land produces coconut and Rice with majority areas as river deltas and sea shore. The area of consideration for the said project is a low land area of Kuttanadu which is spread in the districts of Alappuzha, Kottayam and Pathanamthitta. The majority of the Kuttanadu area is lying below mean sea land. Based on the nature of the soil it can be classified into sand, sandy loam and clay. It is a warm humid region with fairly uniform temperature ranging from $220 \mathrm{c}$ to $350 \mathrm{c}$.

Paddy cultivation is the main agricultural activity in the Kuttanadu area. The paddy fields in Kuttanadu are commonly known as Puncha lands. These puncha lands were vast stretches of water bodies earlier. They were redawned by the local population under the leadership of land lords and were converted to cultivable form for paddy cultivation. The puncha lands of Kuttanadu can be again classified into Karappadam, kayal lands and Kari lands. Karappadam lands are alluvial soil with high amount of acidity and salt contents.

Kayal lands are retained lands from Vembanad Lake and are 1.5 to $2.5 \mathrm{~m}$ below mean sea land. Since it is below MSL the sea water intrudes into these areas and salinity is a great problem. Kari lands are blade peaty acid sulphate soil at or below MSL.

DOI : $10.5121 /$ ijdps.2011.2508 


\subsection{Paddy Cultivation In Kuttanadu}

The cultivation process starts with plowing the field. Two or three rounds of plowing will be done. Then due to south west monsoon the water drenches the field. The level of water in the field may rise to 2.5 to $3 \mathrm{~m}$. In the month of July the water land falls to about $1 \mathrm{~m}$. In this condition one or two rounds of plowing will be done. In the month of September when the water is manageable the organic waste materials and weeds are removed and the soil is raked. Fresh water is collected in the field up to a depth of .25 to $.5 \mathrm{~m}$. Then the seeds are thrown on to the standing water or otherwise the seedlings are transplanted. Once the seeds are set and starts growing the water are pumped out and the field is allowed to dry for 10 days. Lime is applied at this stage and then the water is pumped in to a height of 5 to $8 \mathrm{~cm}$. Fertilizer is applied after draining of the field during tillering and panicle initiation stages of rice plant. The weeding operation is also done when needed. The paddy fields are completely drained 10 days before the harvesting operations.

\subsection{Cultivation Scenario}

The rice cultivation in the Kari lands is not seen to be profitable considering the high cost of labor in Kerala. But as the only crop that can be cultivatable in their vast areas, the farmers are forced to go for paddy cultivation. High yielding varieties of paddy are available but acidity and salinity is a great problem. The farmers are flooding their fields to reduce the effects of these. Since the Kari lands are below MSL the standing water needs to be pumped out during cultivation. All these are done to get a washing effect for these soils to reduce acidity and salinity. However this is not successful as the water hardly penetrates a few $\mathrm{cm}$ near the soil surface. As it is below MSL the water table also high, there by the fresh water will not penetrate the soil. Due to these symptoms of iron ferocity on paddy lands and root decay are common there by going down to a poor yield.

\section{SubSurface Drainage System}

Subsurface Drainage system is a drainage system developed by the Kerala Agricultural University for the above discussed area of Kuttanadu. The objective of the system is to drain the water from the subsurface of the cultivation area. The water will be allowed to get collected in the field and it gets mixed with the iron and salt contents in the soil present there. This water then subsides into the deeper layer of the soil. Through the subsurface drainage system these water will be collected and drained out. Fresh water will be pumped into the field and this process will be continued, there by washing the unwanted minerals in the soil and draining it out.

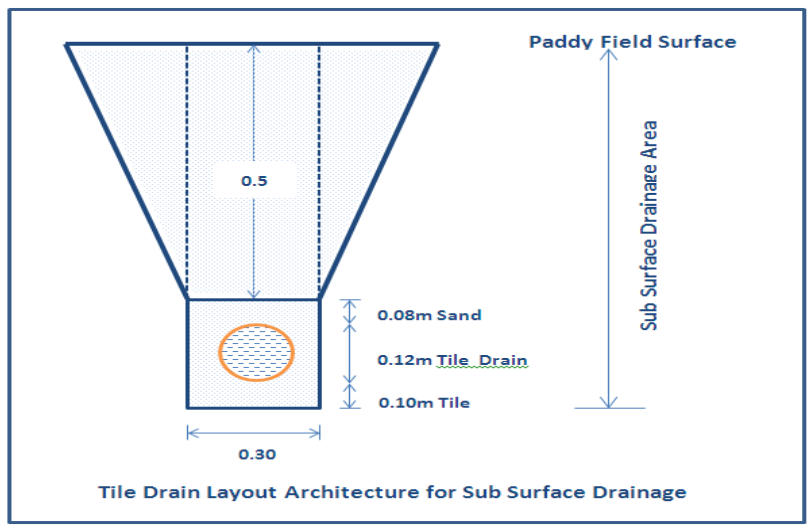


Figure 1. Drain layout

A network of clay or PVC pipes will be laid in the field for this. The water will be entering these pipes and ultimately gets drained out. As per the experiment done by the Kerala Agricultural University nine lines of lateral drains were installed. The first lines close to the main collection sump were at $15 \mathrm{~m}$ spacing and the remaining at $30 \mathrm{~m}$ spacing. Baked clay pipes were used for draining. These drain pipes were of $60 \mathrm{~cm}$ length with an outside diameter of 125 $\mathrm{mm}$ and inside diameter of $100 \mathrm{~mm}$ having bell mouth at one end. They were provided with 15 numbers of $6 \mathrm{~mm}$ holes on 1/3rd of its peripheral area. These holes were arranged in three bands of 5 holes each.

Rigid PVC pipes were used as collector drains to carry the drainage water into the main pump. The filler pipes were laid with slope of $0.2 \%$ and collector pipes with $0.4 \%$ slope. Concrete rings of $60 \mathrm{~cm}$ outside diameter, $50 \mathrm{~cm}$ inside diameter and $5 \mathrm{~cm}$ height were used as collection sumps. Those sumps were placed at the discharge end of each drain line. A much bigger sump is used as the main sump. $5 \mathrm{hp}$ motor pump sets were used to dispose the drained water from the main sump to the outside canals.

\subsection{Observation Wells}

A series of observation wells were installed in the subsurface drained area to record the fluctuations in the water table elevations during drainage. They were made of $40 \mathrm{~mm}$ PVC pipes, each with a length of $1.5 \mathrm{~m} .5 \mathrm{~mm}$ holes with a spacing of $10 \mathrm{~cm}$ were drilled 6 bands at the bottom $50 \mathrm{~cm}$ length and coir was wound around it. The bottom end of the tube is closed to prevent soil entry. The placement of the observation wells in the tile-drained experimental area is as shown in the figure below.

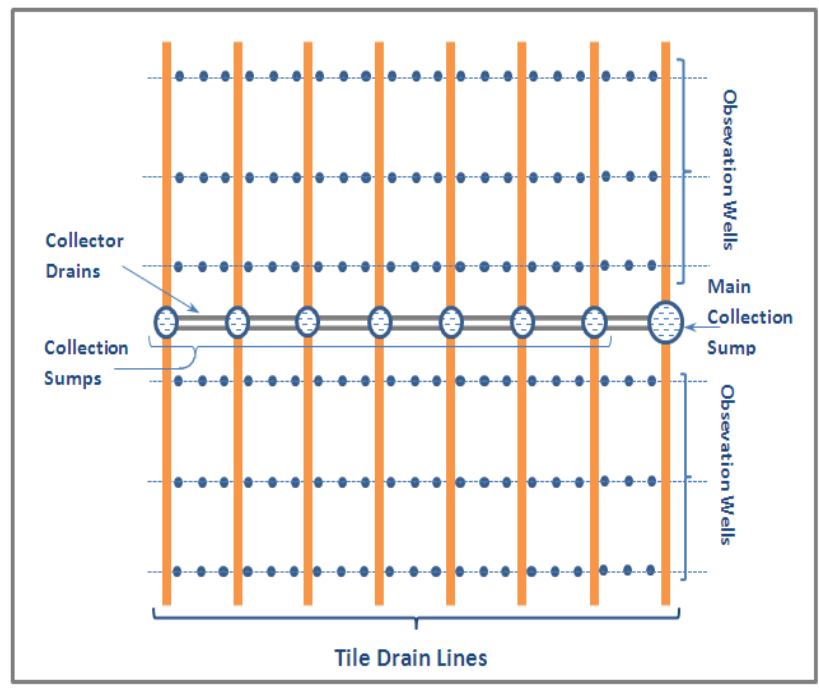

Figure 2. Observation well layout

Observation wells were installed in three bands, each band perpendicular to the drain lines at $\mathrm{L} / 4, \mathrm{~L} / 2$ and $3 \mathrm{~L} / 4$ distances from the discharge end where $\mathrm{L}$ is there length of the drain in meter. The water level in these observation wells are periodically monitored there by obtaining a complete picture of the ground water table of the paddy field. 
However the periodic monitoring of the water table in a limited number of observation wells is possible with human labor, but when it is for a vast area it will not be economical. Even though belonging to many people the paddy fields are normally of very vast area. Therefore applying the technology for a single paddy field may not be economical. Also a governmental or nongovernmental organization can support the group of farmers in that area for adopting the subsurface drainage system.

In a large area of paddy fields of many hectors, hundreds or thousands of observation wells may be necessary for the proper monitoring of the water table. Manual collection of the water level data is a cumbersome and unreliable method. By deploying automated sensors in these wells the data collection process can be simplified and fetches us high amount of data specific to different field conditions.

\section{SYSTEM DESIGN}

The main objective of our system is to measure the data from the observation wells and send it to the central system for processing. The network is planned to be deployed in a huge area of several hectares. There may be hundreds of observation wells and they need to be networked. The entire area may be divided into several groups of about 50 observation wells. These 50 wells will be controlled by a head node. All these head nodes are grouped and they will have their root node. The data from the wells will be sent to their respective head nodes. These data will be processed there and whenever there is a crossing in the threshold level that data will be send to the root node. Initially the water level in all the wells will be considered to be within the constrains. The leaf nodes will be sensing the data periodically and sending to the head node. The head nodes continuously receive the data from their child nodes. They process these data and contact the root node only when the threshold level is reached or crossed. The leaf node or well node should collect the data at prescribed time intervals and to minimize the complication of the systems it will not process the data but it just sends the data to the head node.

Since there are thousands of nodes the traffic will be very high if all the head nodes directly transfer the data to the root node. To avoid this it processes the data from the leaf node to evaluate whether the threshold value is crossed or not. If it has reached or crossed, the message will be passed to the root node. Hence the head nodes should have the mechanisms for processing the data from the leaf nodes.

\subsection{Data Transport Mechanism}

A tree like structure is followed in our system. The leaf level of the tree consists of sensors for obtains the water level in the wells. There may be many such sensors so the power consumption of these devices is critical to the overall performance of the system. Therefore attempts are made to design a sensor node board with low power micro controllers, low power semiconductor based on MEMS sensors, Zigbee IEEE 802.15.4 wireless transceiver. These sensors will collect the data and communicates to the next higher level, the head nodes. 


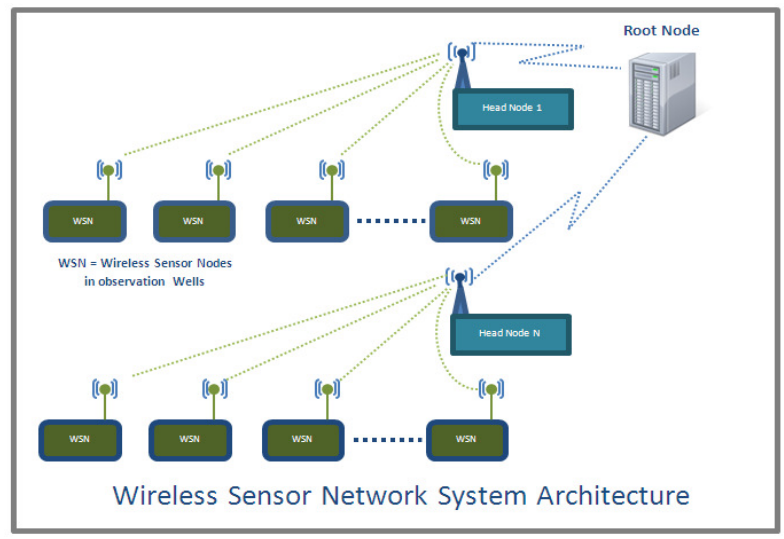

Figure 3. System architecture

These head nodes receive the data through the zigbee module and process it over there. They are also equipped with GPRS Bridge modules for establishing communication with the root server node. By using any GSM network the message will be send to the root server if needed. The initial System architecture is as shown in the figure3.

\subsection{Operational Strategy}

The observation wells will be placed as per the specifications and then the wireless sensor nodes will be attached to them. Periodically it fetches the information and passes it to the head nodes. These head nodes will be working continuously listening for the data packets from their nodes. The received data packets will be stored and processed. it necessary the message will be send to the root server or else the stored data will be send to the server at prescribed time intervals for long time data storage. Upon receiving a warning message from the head nodes the server will process the information and takes necessary actions to overcome the difficulty. The message will be passed to the operator if necessary. If the situation demands it can issue commands to increase the water pumped out quantity from the sumps to decrease the water table level or reduce the same to increase the water table.

\section{Conclusions}

In the recent years science and technology is developing much faster but the agricultural production is decreasing tremendously. This will surely create food shortage and many other economic problems in the near future. Only way to avoid these is to increase the farming practice. The main hindrance for farming is the unavailability of skilled laborers and high cost. Through technologies like precision agriculture and automation of fields we can overcome these difficulties. This paper suggests the possibility of use of wireless sensor networks for the monitoring of water table in vast paddy fields, which is otherwise a tedious job. Through sub surface drainage it is already proved that paddy yield in the Kari lands can be increased to an average of 1.0t/ha over the present yield. If the whole area of Kari lands 9000 ha is brought under the subsurface drainage system it will increase the rice production. We can automate the water table monitoring system there by reducing the cost of labor and implement an almost impossible and tedious project.

\section{REFERENCES}

[1] I. F. Akyildiz and E. P. Stuntebeck, "Wireless underground sensor networks: research challenges,” Ad Hoc Networks, vol.4, no. 6, pp. 669-686, 2006. 
International Journal of Distributed and Parallel Systems (IJDPS) Vol.2, No.5, September 2011

[2] H. R. Bogena, J. A. Huisman, H. Meier, U. Rosenbaum, and A. Weuthen, "Hybrid wireless underground sensor networks:quantification of signal attenuation in soil," Vadose Zone Journal, vol. 8, no. 3, pp. 755-761, 2009.

[3] J. Tiusanen, “Wireless soil scout prototype radio signal reception compared to the attenuation model,” Precision Agriculture, vol. 10, no. 5, pp. 372-381, 2009.

[4] A. R. Silva and M. C. Vuran, "Empirical evaluation of wireless underground-to-underground communication in wireless underground sensor networks," in Proceedings of the 5th IEEE International Conference on Distributed Computing in Sensor Systems (DCOSS '09), vol. 5516 of Lecture Notes in Computer Science, pp. 231-244, Marina del Rey, Calif, USA, June 2009.

[5] Jacques Panchard “Wireless Sensor Networks for Marginal Farming in India” Ingenieur Diplom'e en Syst'emes de Communication (M.Sc.), Ecole Polytechnique F'ed' erale de Lausanne, Suisse A. Arora, R. Ramnath, and E. Ertin. Exscal: Elements of an extreme scale wireless sensor network, 2005.

[6] I.F. Akyildiz, W. Su, Y. Sankarasubramaniam, and E. Cayirci. A Survey on Sensor Networks. IEEE Communications Magazine, Vol. 40, No. 8, 2002 J. Burrell, T. Brooke, and R. Beckwith.

[7] J. Burrell, T. Brooke, and R. Beckwith. "Vineyard computing: sensor networks in agricultural production”.IEEE Pervasive Computing, 3(1):38-45, Jan-Mar 2004.

[8] E K Mathew, Madhusudan Nair, T D Raju, U Jaikumaran,"Drainage Digest” - A report based on two dacades of research under AICRP at Karumady Centre, Kerala, March 2004.

[9] Anurag D, Siuli Roy and Somprakash Bandyopadhyay "Agro-Sense : Precision Agriculture using sensor bases wireless mesh networks” Indian Institute of Management Kolkatta

[10] J. Burrell et al. Vineyard computing: sensor networks in agricultural production. IEEE Pervasive Computing, 3(1):38-45, Jan-Mar 2004.

[11] D.D.Chaudhary, S.P.Nayse, L.M.Waghmare "Application of wireless sensor networks for greenhouse parameter control in precision agriculture” International Journal of Wireless \& Mobile Networks (IJWMN) Vol. 3, No. 1, February 2011

[12] Kavi K. Khedo, Rajiv Perseedoss and Avinash Mungur "A wireless sensor network air pollution monitoring system" International Journal of wireless and mobile networks (IJWMN) Vol.2, No.2, May 2010.

[13] Y. Ma, M. Richards, M. Ghanem, Y. Guo and J. Hassard, "Air Pollution Monitoring and Mining Based on Sensor Grid in London”, Sensors 2008, Vol. 8(6), 3601-3623.

[14] Harry L. Field and John B. Solie, "Introduction to Agricultural Engineering Technology : A Problem Solving Approach", Springer Science \& Business Media, 2007.

[15] Kshitij Shinghal, Dr. Arti Noor, Dr. Neelam Srivastava, Dr. Raghuvir Singh “Intelligent humidity sensor for wireless sensor network agriculture application” International Journal of Wireless \& Mobile Networks (IJWMN) Vol. 3, No. 1, February 2011

[16] K. Mayer, K. Taylor, and K. Ellis. "Cattle health monitoring using wireless sensor networks" In Second IASTED International Conference on Communication and Computer Networks, Cambridge, Massachusetts, USA, Nov. 2004.

[17] R. Beckwith, D. Teibel, and P. Bowen. "Unwired wine: Sensor Networks in Vineyard." In IEEE International Conference on Sensors, 2004.

[18] A. Baggio. “Wireless sensor networks in precision agriculture” In The REALWSN'05 Work-shop on Real-World Wireless Sensor Networks, IVA, Stockholm, June 2005.

[19] G. Barrenetxea, F. Ingelrest, G. Schaefer, M. Vetterli, O. Couach, and M. Parlange. "Sensor Scope: Out-of-the-Box Environmental Monitoring" In The 7th International Conferenceon Information Processing in Sensor Networks (IPSN 2008), St. Louis, Missouri, USA,2008. 
International Journal of Distributed and Parallel Systems (IJDPS) Vol.2, No.5, September 2011

Santhosh Simon has been working as a Lecturer of Department of Computer Science at St.Thomas College of Engineering and Technology, Kerala, India and a research student of Cochin University of Science and Technology. He has acquired BTech and MTech degree in Computer Science. He has presented research papers in several National and International conferences. His research interests are in Artificilal Intelligence, Sensor Networks and Robotics. Santhosh Simon is a Professional Member of ISTE and IEEE.

K Poulose Jacob Professor of Computer Science at Cochin University of Science and Technology since 1994, is currently Director of the School of Computer Science Studies there. A National Merit Scholar all through, Dr. Jacob has been teaching at the Cochin University since 1980. He has presented research papers in several International Conferences in Europe, USA, and other countries. Dr. K.Poulose Jacob is a Permanent Professional Member of the ACM and a Life Member of the CSI. His research interests are in Information Systems Engineering, Intelligent Architectures

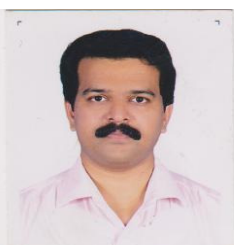
and Networks.

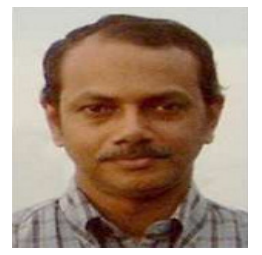

